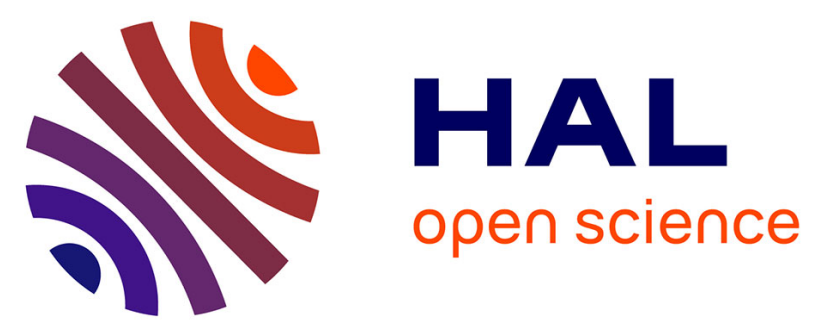

\title{
Disclosing Interfaces of ZnO Nanocrystals Using Dynamic Nuclear Polarization: Sol-Gel versus Organometallic Approach
}

Daniel Lee, Malgorzata Wolska-Pietkiewicz, Saumya Badoni, Agnieszka Grala, Janusz Lewiński, Gaël de Paëpe

\section{To cite this version:}

Daniel Lee, Malgorzata Wolska-Pietkiewicz, Saumya Badoni, Agnieszka Grala, Janusz Lewiński, et al.. Disclosing Interfaces of ZnO Nanocrystals Using Dynamic Nuclear Polarization: Sol-Gel versus Organometallic Approach. Angewandte Chemie International Edition, 2019, 58 (48), pp.17163-17168. 10.1002/anie.201906726 . hal-03356724

\section{HAL Id: hal-03356724 https://hal.science/hal-03356724}

Submitted on 28 Sep 2021

HAL is a multi-disciplinary open access archive for the deposit and dissemination of scientific research documents, whether they are published or not. The documents may come from teaching and research institutions in France or abroad, or from public or private research centers.
L'archive ouverte pluridisciplinaire $\mathbf{H A L}$, est destinée au dépôt et à la diffusion de documents scientifiques de niveau recherche, publiés ou non, émanant des établissements d'enseignement et de recherche français ou étrangers, des laboratoires publics ou privés. 


\title{
Disclosing Interfaces of ZnO Nanocrystals Using Dynamic Nuclear
}

\section{Polarization: Sol-Gel versus Organometallic Approach}

\author{
Daniel Lee, ${ }^{\dagger[a]}$ Małgorzata Wolska-Pietkiewicz, ${ }^{+[b]}$ Saumya Badoni, ${ }^{[a]}$ Agnieszka Grala, ${ }^{[c]}$ Janusz \\ Lewiński $^{*[b, c]}$ and Gaël De Paëpe ${ }^{*[a]}$
}

\begin{abstract}
The unambiguous characterization of the coordination chemistry of nanocrystal surfaces that have been produced by a wetchemical synthesis presently remains a highly challenging issue. Here, zinc oxide nanocrystals ( $\mathrm{ZnO} \mathrm{NCs}$ ) coated by monoanionic diphenyl phosphate (DPP) ligands were derived by a traditional sol-gel process and a one-pot self-supporting organometallic (OSSOM) procedure, and advanced atomic-scale characterization through dynamic nuclear polarization (DNP-)enhanced solid-state nuclear magnetic resonance (ssNMR) spectroscopy has notably enabled resolving their vastly different surface-ligand interfaces. For the OSSOM-derived NCs, DPP moieties form stable and strongly-anchored $\mu_{2}$-and $\mu_{3}$-bridgingligand pairs that are resistant to competitive ligand exchange processes. Contrastingly, the sol-gel-derived NCs contain a wide variety of coordination modes of DPP ligands and a ligand exchange process takes place between DPP ligands and glycerol molecules. This highlights the power of DNP-enhanced ssNMR for detailed NC surface analysis and the superiority of the OSSOM approach for the preparation of high quality $\mathrm{ZnO}$ NCs.
\end{abstract}

Zinc oxide $(\mathrm{ZnO})$ is a versatile material of long-standing interest due to its unique catalytic and electro-optical characteristics. ${ }^{1}$ The inherent and distinctive physicochemical properties of $\mathrm{ZnO}$ nanocrystals (NCs) are dependent on a variety of factors that are largely determined by the applied synthetic procedure and the character of the resulting nanocrystal-ligand interface including intimate interactions on NC surfaces, the surface ligand dynamics, ligand packing density, and their binding mode and/or affinity. In this regard, classical wet-inorganic sol-gel methodology has played a key role in advancing ZnO NC science by providing access to a multitude of tailored nanostructures. ${ }^{2}$ While this process is versatile, it showcased some significant drawbacks. ${ }^{\text {Erreur ! Signet non défini.b,3 }}$ For instance, the reproducibility of this method can be hardly regulated as the formation of quantum-sized $\mathrm{ZnO} N \mathrm{NC}$ is kinetically controlled. The lack of direct control over the fast NC formation at the stage of quantum-sized crystals $^{2 a, b}$ likely inhibits both the uniformity of particle morphology and nanocrystal-ligand interface composition, including the density and homogeneity of any ligand shell. ${ }^{4}$ It could also be

\footnotetext{
[a] Dr D. Lee, Dr G. De Paëpe

Univ. Grenoble Alpes, CEA, INAC-MEM, 38000 Grenoble, France

E-mail: gael.depaepe@cea.fr

[b] Dr M. Wolska-Pietkiewicz, Prof. J. Lewiński

Faculty of Chemistry, Warsaw University of Technology,

Noakowskiego 3, 00-664 Warsaw, Poland

E-mail: lewin@ch.pw.edu.pl

[c] Dr A. Grala, Prof. J. Lewiński

Institute of Physical Chemistry, Polish Academy of Sciences,

Kasprzaka 44/52, 01-224 Warsaw, Poland

$+\quad$ These authors contributed equally to this work.
}

Supporting information for this article is given via a link at the end of the document. related with an inherently highly-defected and corrugated surface structure, and an unstable resulting nanocrystal-ligand interface (e.g., Gong et al. demonstrated that sol-gel derived ZnO NCs with a stable surface structure could be achieved after a one-month aging process $\left.{ }^{4 f}\right)$. An alternative to the omnipresent sol-gel method are highly promising wet-organometallic approaches. ${ }^{5,6}$ In this regard, Chaudret and co-workers pioneered the preparation of $\mathrm{ZnO} \mathrm{NCs}$, utilizing dicyclohexylzinc as the precursor in the presence of long-chain amines acting as L-type ligands, ${ }^{5}$ where the resulting amine-stabilizing layer has the 'dynamic structure, ${ }^{5 d, 7}$ More recently, we have elaborated the one-pot selfsupporting organometallic (OSSOM) procedure based on the controlled exposition of a [EtZn(X)]-type precursor $(X=$ monoanionic organic ligand) to air leading to $\mathrm{ZnO} N C$ s coated with an organic shell composed of surface-anchored X-type ligands. ${ }^{8}$ The OSSOM process is thermodynamically controlled and affords stable, bio-safe ${ }^{8 \mathrm{e}}$ and well-passivated $\mathrm{ZnO}$ NCs with ultra-long-lived luminescence. ${ }^{8 e, 9}$

To gain a better understanding of how the interface between the inorganic core and the organic shell relates to observed synthetic procedure-driven properties, ZnO NCs coated with monoanionic diphenyl phosphate (DPP) ligands were prepared by both the OSSOM and sol-gel methods as representative nanosystems (abbreviated as OM NCs and SG NCs, respectively; for experimental details see the Supporting Information). We selected the diorganophosphate anchoring ligand due to intriguing structural properties and the $100 \%$ naturally abundant NMR-active nucleus of phosphorus, ${ }^{31} \mathrm{P}$. Then we applied $9.4 \mathrm{~T}$ solid-state NMR combined with magic angle sample spinning and dynamic nuclear polarization (MAS-DNP), ${ }^{10}$ which has recently proven invaluable for specialized surface studies, ${ }^{11}$ including for quantum dots. ${ }^{12}$ In addition, to test the stability of the ZnO NCs toward chemical environment, a solvent matrix containing glycerol was chosen for the MAS-DNP experiments.

STEM micrographs and DLS analysis of the OM NCs show well-dispersed and nearly spherically shaped particles with a core mean diameter of $4.8 \pm 0.5 \mathrm{~nm}$ (the average NC's size calculated from PXRD is equal to $4.4 \pm 1 \mathrm{~nm}$ ) and a hydrodynamic diameter of $9.6 \mathrm{~nm}(\mathrm{PDI}=0.083$ ) (see Figure S1 and Figure S2 in the Supporting Information). In contrast, the standard sol-gel method provided significantly larger NCs with a core size of 10-12 nm ( $10 \pm 1.8 \mathrm{~nm}$ calculated from PXRD), though their aggregation and irregular shape prevented a more exact size distribution analysis (note that the aggregation and formation of a colloidal suspension of the SG NCs prevented reliable DLS measurements). The PXRD patterns for OM and SG NCs are consistent with a hexagonal wurtzite-type $\mathrm{ZnO}$ phase (see Figure S3). Both sets of NCs revealed a broad absorption in the UV region and emission maxima centered at 525 and $555 \mathrm{~nm}$, respectively (see Figure S4 and Figure S5). The FTIR spectra confirm that DPP passivating moieties are deprotonated (see Figure S6), which corroborate the thermogravimetric analysis (see Figure S7). In the TGA profile of 

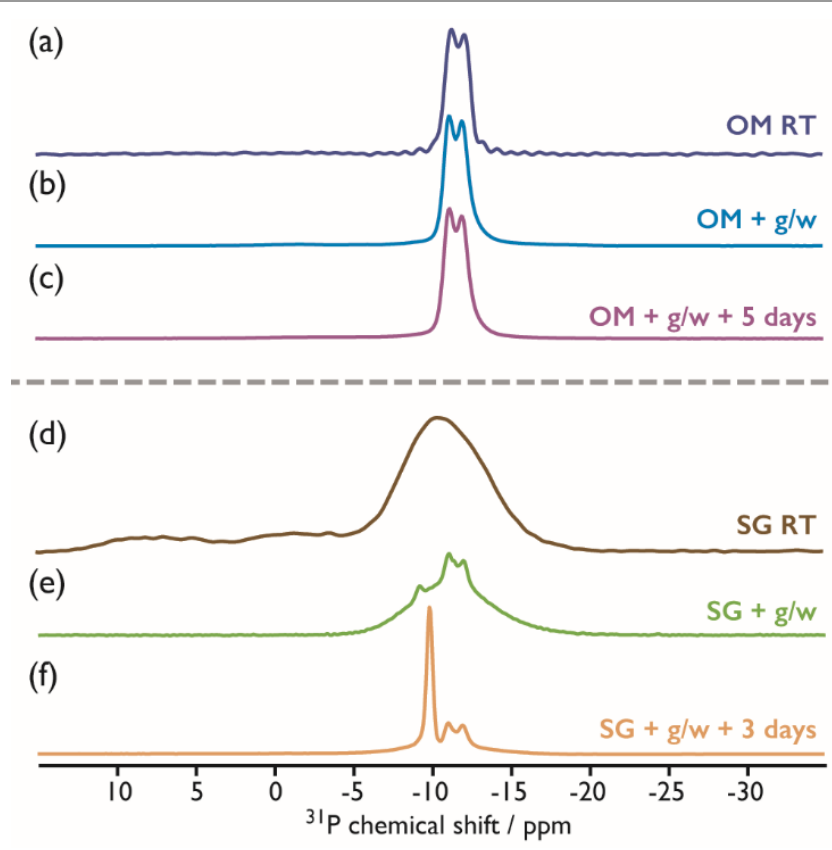

Figure 1. Time-dependent room temperature $(a, d)$ and $105 \mathrm{~K}$ DNP-enhanced $(b, c, e, f)\left\{{ }^{1} \mathrm{H}-\right\}^{31} \mathrm{P}$ CPMAS NMR spectra of $(\mathrm{a}, \mathrm{b}, \mathrm{c})$ organometallic and $(\mathrm{d}, \mathrm{e}, \mathrm{f})$ sol-gel derived ZnO NCs. (b, e) Spectra recorded within 30 minutes of addition of glycerol/water $(\mathrm{g} / \mathrm{w})$ solution and $(\mathrm{c}, \mathrm{f})$ after storage at $-18^{\circ} \mathrm{C}$.

the OM NCs only one main decomposition step in the range from $0^{\circ} \mathrm{C}$ to $500^{\circ} \mathrm{C}$ is present. On the contrary, the SG system shows a significantly more complex decomposition path. This observation substantiates the different nanocrystal-ligand interfaces for NCs derived from the OSSOM and sol-gel methods, and indicates a more complex structure of organic ligand shell for the SG NCs. The TGA-determined surface coverage of OM and SG NCs were ca. 4-5 ligands $/ \mathrm{nm}^{2}$ and 12 ligands $/ \mathrm{nm}^{2}$, respectively. ${ }^{13} \mathrm{~A}$ comparison of the characteristic properties of the OM and SG NCs is presented in Figure S8 in the SI.

Subsequently, the structures of the organic ligand shells were compared using NMR spectroscopy, which has recently been shown to be particularly powerful in this regard. ${ }^{14}$ Figure 1 shows the $\left\{{ }^{1} \mathrm{H}-\right\}^{31} \mathrm{P}$ cross-polarization (CP) MAS NMR spectra of OM and SG NCs (Figure 1a and 1d) and corresponding DNPenhanced spectra recorded for freshly wetted samples (Figure $1 \mathrm{~b}$ and $1 \mathrm{e}$ ) as well as after sample storage at $-18^{\circ} \mathrm{C}$ for 5 and 3 days, respectively (Figure 1c and 1f). The NMR spectra highlight that the surface of the OM NCs is indeed functionalized by monoanionic diphenyl phosphate ligands, evidenced by ${ }^{31} \mathrm{P}$ NMR signals at $\delta\left\{{ }^{31} \mathrm{P}\right\} \approx-11$ and -12 ppm (F.W.H.H. $\sim 120 \mathrm{~Hz}$ ) that are inconsistent with pure DPP-H (see Figure S9a), whereas they are consistent with the chemical shift of bridging DPP, as observed in model organozinc molecular complexes. ${ }^{15}$ The relatively narrow linewidth of the two ${ }^{31} \mathrm{P}$ peaks indicates a rather ordered structure at the surface. In addition, the time-dependent spectra show that the OM NCs remain stable (Figure $1 \mathrm{~b}$ and 1c), which indicates that the resulting nanocrystal-ligand interface is robust.

In contrast, the respective spectra of the SG NCs (Figure $1 \mathrm{~d}-\mathrm{f})$ are far more complex. The initial, "pre-wetting" spectrum (Figure 1d) features unsymmetrical broad signals ranging from approximately 15 to $-15 \mathrm{ppm}$, indicating a dramatically
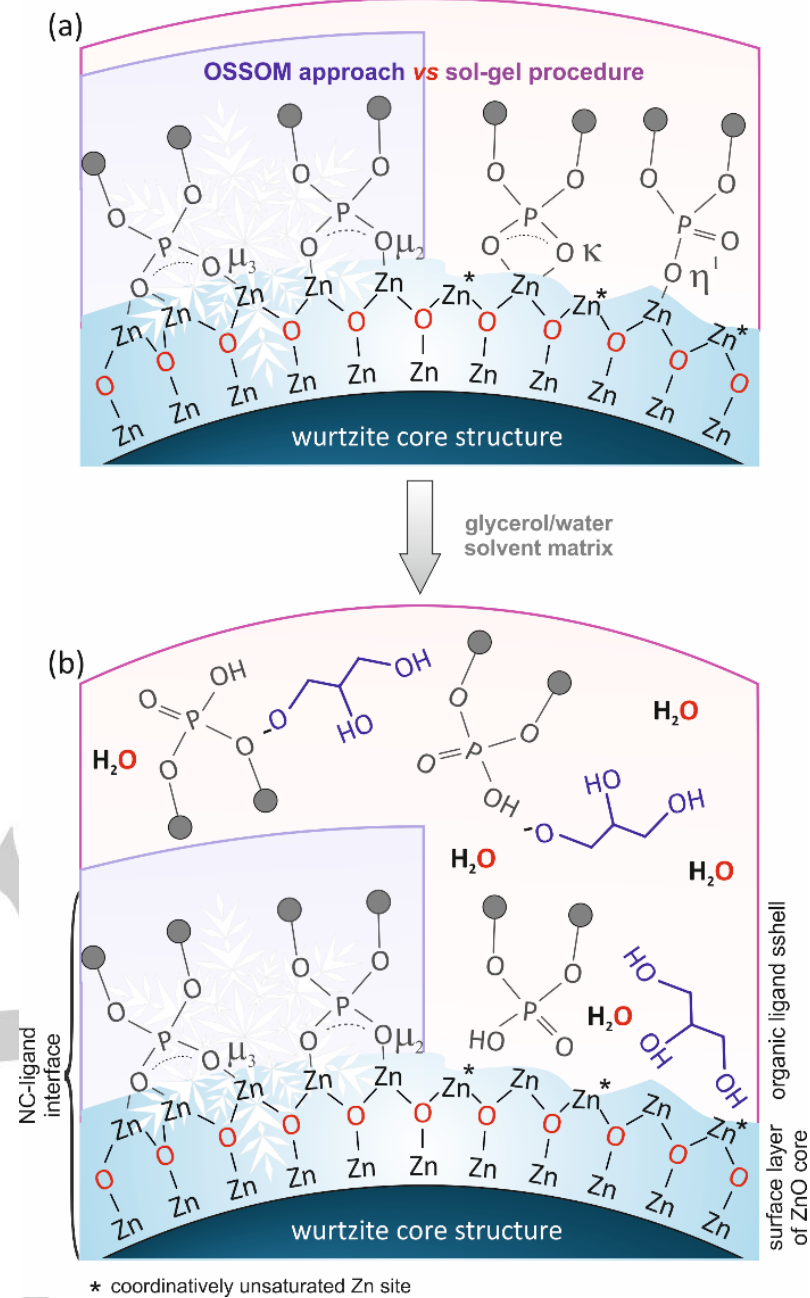

Figure 2. Schematic representation of the organic ligand shell of OM and SG NCs before (a) and after (b) wetting and aging with a glycerol-based matrix. The snowflake represents a surface portion with an ordered and stable ligand arrangement (i.e. stable $\mu_{2}$ - and $\mu_{3}$ - DPP-bridging-ligand pairs), termed here as cold spots. Residual acetate moieties present on the surface of SG NCs are omitted for clarity.

different organic-inorganic interface to that in OM NCs. Furthermore, the spectrum of the "just-wetted" SG NCs (Figure 1e) consists of evolving broad contributions (ranging from $\delta\left\{{ }^{31} \mathrm{P}\right\}$ $\approx-5$ to $-15 \mathrm{ppm}$ ) and also the emergence of narrow peaks at $\delta\left\{{ }^{31} \mathrm{P}\right\}$ $\approx-11$ and $-12 \mathrm{ppm}$ (corresponding to those observed for the OM $\mathrm{NCs}$ ) along with an additional signal at $\approx-9 \mathrm{ppm}$ (Figure 1e). After 3 days' storage at $-18^{\circ} \mathrm{C}$, the spectrum has significantly evolved (Figure 1f) to leave the narrow signals at $\delta\left\{{ }^{31} \mathrm{P}\right\} \approx-11$ and $-12 \mathrm{ppm}$ (as a minor component) and to produce a separate intense signal at $\approx-10 \mathrm{ppm}$ (as a major component). The latter signal is associated with the solvent-matrix-induced release of DPP species from the surface of the SG NCs in the protonated form as DPP-H (Figure 2), which results in the same $\delta\left\{{ }^{31} \mathrm{P}\right\}$ as observed for the pure DPP-H pro-ligand (see Figure S9a). The relatively narrow linewidth of the signal at $\delta\left\{{ }^{31} \mathrm{P}\right\} \approx-10 \mathrm{ppm}$ suggests that although the ligand has been detached from the surface, it is in an ordered environment (i.e. DPP-H molecules interact with the solvent matrix). A broad peak would be expected for a lessordered environment, such as found in a DPP-H solution (see 
Figure S9a). A large range of ${ }^{31} \mathrm{P}$ chemical shifts and the observed changes in the time-dependent $\left\{{ }^{1} \mathrm{H}-\right\}^{31} \mathrm{P}$ cross-polarization (CP) MAS NMR spectra data clearly indicate that SG NCs possess a corrugated NC surface structure composed of islands and ridges with variously coordinated, and potentially multi-layered, organic ligands (Figure 2). Moreover, the data demonstrate that the organic-inorganic interface of these NCs is not stable toward chemical environment and a ligand exchange process takes place between DPP ligands and glycerol molecules (see Figure 2). ${ }^{16}$ Possible hydrogen-bond formation between the resulting anionic glycerol species and DPP-H molecules as well as between glycerol and the residual DPP ligands present on the surface could force some short range order. The next- and second nextneighboring molecules probably also align similarly, leading to the formation of a multi-layered structure described previously as a 'swollen' shell (i.e. the organic shell is not built up by a closelypacked monolayer of DPP molecules but is rather a swollen coating composed of DPP and solvent molecules). ${ }^{4 e}$ Moreover, for the time-evolved SG NCs, the small relative intensities of the narrow signals from the remaining surface-bound DPP ligands compared to the signal from the surface-detached DPP-H moieties suggests that the $\mathrm{ZnO}$ surface produced from the sol-gel synthesis is characterized by the presence of only very limited and randomly distributed robust surface islands with an ordered and stable ligand arrangement, which we have termed "cold spots". These sparse and relatively stable spots then have a similar local structure to that of the entire surface of the $\mathrm{ZnO}$ NCs derived from the OSSOM approach (Figure 2). An estimation of the amount of detached DPP-H molecules can be obtained from the ${ }^{31} \mathrm{P}$ NMR spectrum of Figure $1 \mathrm{f}$ (assuming that the CP dynamics are similar for surface-bound and free ligand moieties). This analysis (see Figure S10) shows that approximately one quarter of the ligands remain surface-bound, half are in the semi-ordered swollen shell, and the remaining quarter are randomly distributed in the solvent.

To further characterize the effect of the glycerol/water solvent matrix on the DPP ligand shell in the SG and OM NCs, time-dependent DNP-enhanced $\left\{{ }^{1} \mathrm{H}-\right\}^{13} \mathrm{C}$ CPMAS NMR spectra (Figure 3 and Figure S11) along with DNP-enhanced $2 \mathrm{D}{ }^{13} \mathrm{C}-{ }^{31} \mathrm{P}$ correlation spectra (Figure S13) were acquired. The ${ }^{13} \mathrm{C}$ NMR data indicate that the OM sample remained unaffected during sample storage and the surface-bound DPP ligands are highly ordered, with at least $20{ }^{13} \mathrm{C}$ resonances for the DPP moieties of OM NCs (suggesting more than one DPP environment, see Figure 3). In contrast, the respective spectra of the SG NCs (Figure 1d) are far more complex. There is a change in the ${ }^{13} \mathrm{C}$ NMR signals stemming from glycerol for the SG sample with time (Figures $3 \mathrm{c}$ and $3 \mathrm{~d}$ ). Two narrow peaks (denoted by asterisks on Figure $3 d$ ) are observed to evolve from the broad peaks typical of a glycerol/water glassy matrix. These narrow peaks together with the pattern characteristic for DPP-H molecules (particularly when compared to pure pro-ligand, see Figure S9b) infer the presence of an ordered system within a 'swollen' shell around SG NCs. Furthermore, a close proximity is detected between ${ }^{31} \mathrm{P}$ from surface-detached DPP-H moieties $\left(\delta\left\{{ }^{31} \mathrm{P}\right\} \approx-10 \mathrm{ppm}\right)$ and ${ }^{13} \mathrm{C}$ of ordered glycerol in $2 \mathrm{D}{ }^{13} \mathrm{C}-{ }^{31} \mathrm{P}$ correlation spectra (see Figure S13) but this is not the case for surface-bound DPP species, which strongly supports this concept of a 'swollen' organic shell ${ }^{4 \mathrm{e}}$ surrounding SG NCs. Strikingly, the ${ }^{13} \mathrm{C} N M R$ data also shows

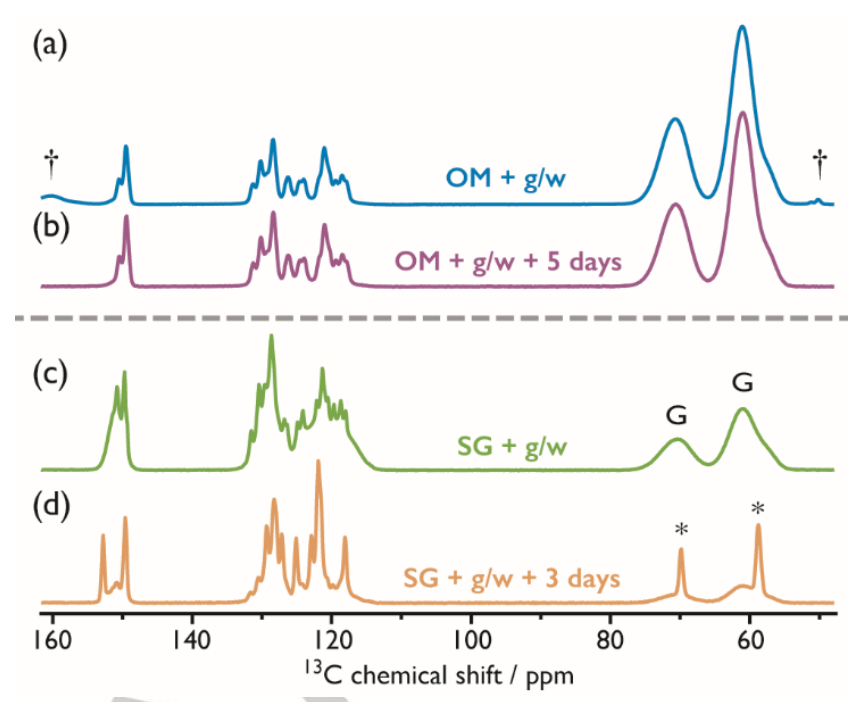

Figure 3. Time-dependent $105 \mathrm{~K}$ DNP-enhanced $\left\{{ }^{1} \mathrm{H}-\right\}^{13} \mathrm{C}$ CPMAS NMR spectra. (a, b) Organometallic and (c, d) sol-gel derived ZnO NCs. "G" and "** denote signals from amorphous and crystalline glycerol, respectively, and " $\dagger$ " denotes spinning side bands. The MAS frequency for (a) was $10 \mathrm{kHz}$, whereas $13.889 \mathrm{kHz}$ was used for $(\mathrm{b}-\mathrm{d})$.

that the sol-gel approach, which used zinc acetate as a precursor, results in residual acetate as well as DPP ligands on the surface of $\mathrm{ZnO}$ NCs (see Figure S11). The DPP ligands occupy the anticipated cold spot and residual acetates are likely encapsulated in niches on corrugated surface structures of the SG NCs. The latter observation corroborates earlier studies reported by Peukert et al. ${ }^{4 \mathrm{~b}}$ in which it was evidenced that acetate moieties could be continuously detached from organic coatings upon purification and only a small amount of coordinated acetate remains at $\mathrm{ZnO} \mathrm{NC}$ surfaces.

The intimate interactions between organic ligands and NC surfaces (binding mode and/or affinity etc.) are crucial for the structure-property relationship of $\mathrm{ZnO}$ NCs. Thus, for a more detailed study of the organic ligand shell, 2D NMR spectroscopy was employed. Figure 4 shows DNP-enhanced 2D ${ }^{31} \mathrm{P}$ homonuclear dipolar correlation spectra of the wetted and aged OM NCs, recorded using the $S_{3}$ recoupling sequence ${ }^{17}$ with short (Figure 4a) and long (Figure 4b) dipolar recoupling times. This experiment produces peaks that share a common frequency (or double-quantum (DQ) chemical shift) in the horizontal dimension for nuclei that are spatially close to one another. Interestingly, a short recoupling time (Figure 4a) shows that the two ${ }^{31} \mathrm{P}$ signals with $\delta\left\{{ }^{31} \mathrm{P}\right\} \approx-11$ and $-12 \mathrm{ppm}$ stem from two discrete but adjacent DPP bridging ligands, denoted here as $P_{1}$ and $P_{2}$. Moreover, there is no evidence in this spectrum of these sites showing autocorrelation peaks, i.e. a surface-bound DPP is not spatially close to another DPP moiety with the same conformational environment (and thus chemical shift). Therefore, the surfacebound DPP is only spatially very close to a second DPP moiety that has a different conformation, likely resulting from pairs on polar facets of the NCs. At longer recoupling times (Figure 4b) connections between $P_{1}$ and another $P_{1}$ site as well as $P_{2}$ and other $P_{2}$ sites become present. This means that there is some proximity between $P_{1} / P_{2}$ and other $P_{1} / P_{2}$ environments but that $P_{1}$ environments are much closer to dissimilar $P_{2}$ environments. 


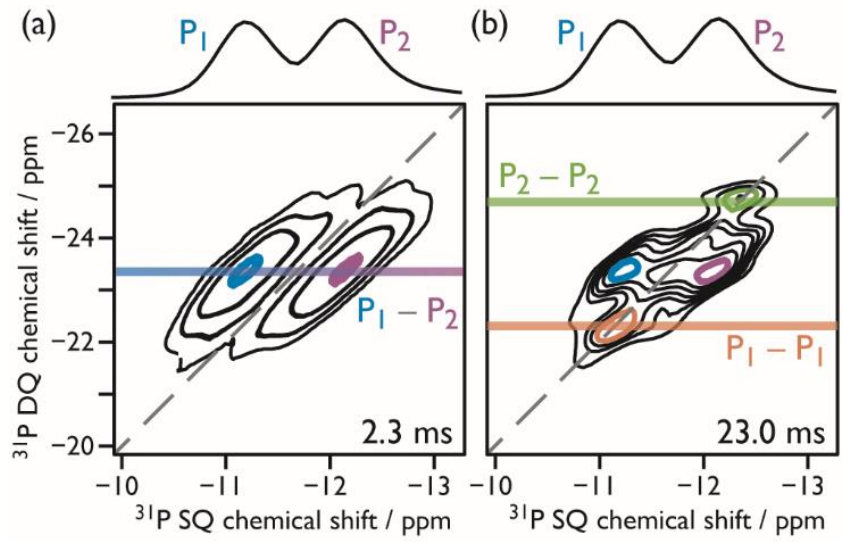

(c) $\circ P_{1}-P_{2} ; \delta\left\{P_{1}\right\} \square P_{1}-P_{2} ; \delta\left\{P_{2}\right\}$ - $P_{1}-P_{1} ; \delta\left\{P_{1}\right\} \square P_{2}-P_{2} ; \delta\left\{P_{2}\right\}$

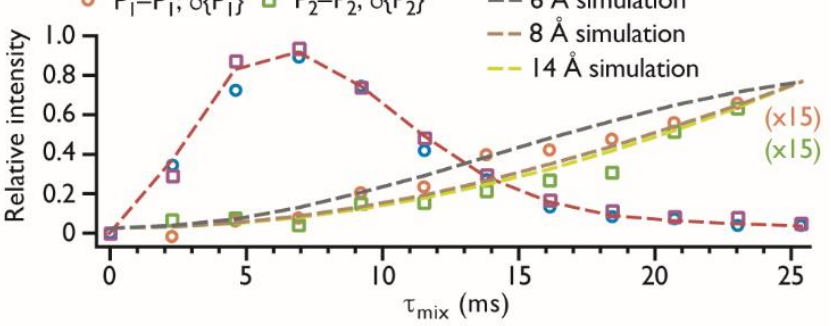

(d)

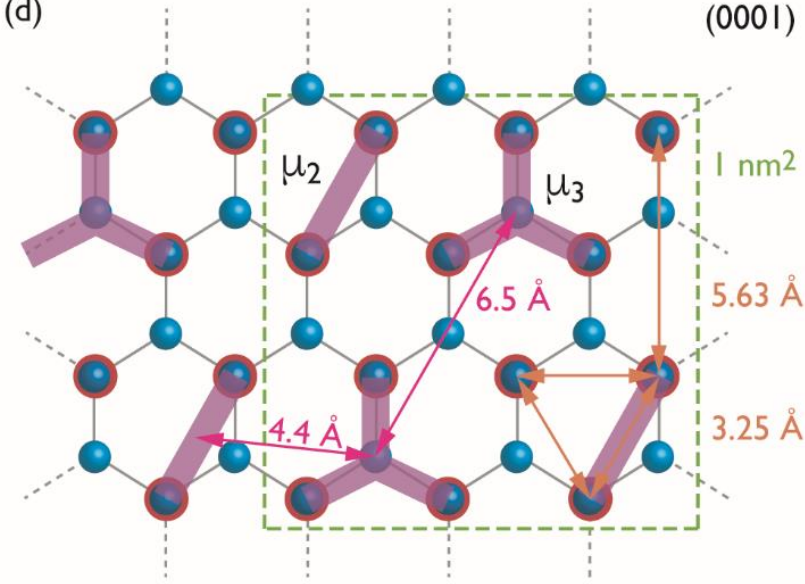

Figure 4. Representative DNP-enhanced ${ }^{31} \mathrm{P}-{ }^{31} \mathrm{P} \mathrm{S}_{3}$ dipolar correlation spectra recorded with a total $\mathrm{S}_{3}$ recoupling time, $\tau_{\text {mix }}$, of (a) $2.3 \mathrm{~ms}$ and (b) $23 \mathrm{~ms}$, along with (c) a plot showing the relative intensities of $P_{1}-P_{2}$ and $P_{1}-P_{1}$ and $P_{2}-P_{2}$ correlations peaks as a function of $\tau_{\text {mix }}$, with corresponding SPINEVOLUTION simulations (dashed lines) based on the internuclear distances given and on the schematic wurtzite (0001) surface structure shown in (d).

Comparative 2D ${ }^{31} \mathrm{P}$ homonuclear dipolar correlation spectra for the SG NCs (I) show that the surface-dissociated (solvated or swollen shell) DPP-H moieties with $\delta\left\{{ }^{31} \mathrm{P}\right\}=-10 \mathrm{ppm}$ display an autocorrelation peak (at $\delta\left\{{ }^{31} \mathrm{P}_{\mathrm{DQ}}\right\}=-20 \mathrm{ppm}$, see Figure S14) arising from a proximity between these released molecules and (ii) exhibit $P_{1}-P_{2}$ connections at short recoupling times as well as $P_{1}-P_{1}$ and $P_{2}-P_{2}$ connections at longer recoupling times, as found for the OM NCs. This latter observation substantiates the conclusion of sparse cold spots on the surface of the SG NCs having the same stable ligand arrangement as the $\mathrm{ZnO} N C$ surfaces produced from the OSSOM approach.
For the estimation of distances between ${ }^{31} \mathrm{P}$ nuclei, and thus between DPP moieties, multiple 2D ${ }^{31} \mathrm{P}$ homonuclear dipolar correlation experiments were performed with varying dipolar recoupling times $\left(\tau_{\text {mix }}\right)$. Plotting the intensity of the OM NC $P_{1}-P_{2}$ correlation peaks (at $\delta\left\{{ }^{31} \mathrm{P}_{\mathrm{DQ}}\right\}=-23.4 \mathrm{ppm}$ ) as a function of $\tau_{\text {mix }}$ and comparing the resulting curve to numerical simulations using SPINEVOLUTION ${ }^{18}$ software gives a good fit for a discrete internuclear $P-P$ distance of $4.1 \pm 0.2 \AA$ (see Figure S15a). The presence of surface dianionic tetraphenyl pyrophosphate moieties (resulting from a condensation reaction between two DPP-H pro-ligands) can be ruled out since this would result in a ${ }^{31} \mathrm{P} \_{ }^{31} \mathrm{P}$ internuclear distance of approximately $3 \AA$. The presence of monoanionic ligands, either monodentate or bidentate $\left(\kappa, \mu_{2-}\right.$ $\eta^{1}: \eta^{1}$ or $\mu_{3}-\mu_{2}: \eta^{1}$ bridging coordination modes), would result in ${ }^{31} \mathrm{P}$ internuclear distances either $<3.5$ or $>4.9 \AA$ between DPP ligands on wurtzite NCs, except if pairs of $\mu_{2}-\mu_{3}$ ligands are formed on wurtzite (0001) surfaces (see Figure S16). Therefore, with the estimated $P_{1}-P_{2}$ distance of $\sim 4.1 \AA$, some surface DPP moieties must be arranged close together, forming these $\mu_{2}-\mu_{3}$ pairs (on wurtzite (0001) surfaces), possibly stabilized through $\pi-\pi$ interactions of the DPP aromatic rings. Accordingly, $P_{1}$ and $P_{2}$ must be from $\mu_{2}-\eta^{1}: \eta^{1}$ and $\mu_{3}-\mu_{2}: \eta^{1}$ ligands (not necessarily respectively). Taking this surface structure, depicted in Figure $4 d$, for the numerical simulations (rather than simple $P-P$ pairs) results in a revised estimate for the $P_{\mu 3}-P_{\mu 2}$ internuclear distance, giving $4.4 \pm 0.2 \AA$ (see Figure 4c). A $P_{1}-P_{1}$ (or $P_{2}-P_{2}$ ) distance from the proposed wurtzite (0001) ZnO-DPP surface configuration would be $>6 \AA$ and from other polar surfaces (such as $(10 \overline{1} \overline{1}$ ), see Figure S16) it would be at least $5 \AA$. This is what is found from comparing numerical simulations to experimental data (see Figure 4c), using a similar correlation peak analysis as above. This surface characterization indicates that a very compact coverage is possible for the OM NCs, in agreement with the TGA analysis that gives $4-5$ ligands per $\mathrm{nm}^{2}$. It could thus be proposed that the thermodynamically-controlled OSSOM approach and the utility of monoanionic stabilizing ligands, which could strongly and formation-selectively adsorb to the polar (0001) face, allow for lower aspect-ratio (i.e. quasi-spherically shaped) ZnO NCs with significantly more [0001] planes present. This is consistent with the literature ${ }^{19}$ and the observed relatively high surface coverage of the $\mathrm{ZnO}$ NCs derived from the organometallic approach, with this type of information being a considerable challenge to currently obtain for organic-ligand-coated small-sized NCs using electron microscopy techniques.

The same correlation peak analysis was also performed for the surface-detached DPP-H observed for the SG NCs, which indicates one large internuclear P-P distance of $\sim 10 \AA$ (see Figure $\mathrm{S} 15 \mathrm{~b}$ ). This is consistent with an ordered swollen shell containing glycerol molecules hydrogen-bonded between DPP molecules (see schematic in Figure S17). It should be noted that no interactions between detached and surface-bound species were observed. The surface characterization of the wetted SG NCs then indicates that a mixture of sparse, randomly distributed surface cold spots containing stable $\mu_{2^{-}}$and $\mu_{3}$-DPP-bridgingligand pairs, and above-surface ordered DPP-H molecules in probable multi-layers, consistent with the TGA analysis that gives the large number of 12 ligands per $\mathrm{nm}^{2}$ of NC surface.

In conclusion, DNP-enhanced solid-state NMR spectroscopy proves extremely pertinent for detailed 
characterization of nanocrystal-ligand interfaces, here highlighting large differences between DPP-coated ZnO NCs prepared by the organometallic approach and the traditional solgel procedure. It has been shown that the OSSOM approach provides $\mathrm{ZnO} \mathrm{NCs}$ with a highly-ordered surface ligand arrangement of $\mu_{2}-\eta^{1}: \eta^{1}-\mathrm{DPP}_{1}$ and $\mu_{3}-\mu_{2}: \eta^{1}-\mathrm{DPP}_{2}$ bridging ligands which are paired-up on the surface and which remain unaffected during sample storage and even in the presence of glycerol as a highly competitive capping ligand. In contrast, $\mathrm{ZnO}$ NCs produced via the sol-gel method exhibit variously-coordinated DPP ligands and a time-dependent surface restructuring process with a displacement of the majority of the ligands from the surface, creating an ordered swollen shell containing DPP-H and solvent molecules, signifying a corrugated surface morphology of these NCs and substantially labile surface-ligand interactions. Moreover, in the case of SG NCs, the presence of randomly distributed robust surface islands with an ordered and stable ligand arrangement were evidenced.

\section{Acknowledgements}

J.L. and M.W.-P. acknowledge the Foundation for Polish Science Team Program co-financed by the European Union under the European Regional Development Fund POIR.04.04.00-0020C6/16-00 (TEAM/2016-2/14) and G.D.P. acknowledges the French National Research Agency (ANR-12-BS08-0016-01, ANR-11-LABX-0003-01 and RTB) and the European Research Council (ERC-CoG- 2015, No. 682895), for financial support. We thank Dr. J. Grzonka (Faculty of Materials Science and Engineering, Warsaw University of Technology) for assistance with STEM imaging.

Keywords: dynamic nuclear polarization - nuclear magnetic resonance $\cdot$ surface characterization $\cdot$ synthesis $\cdot$ zinc oxide

[1] a) H. Morkoç, U. Özgür, Zinc Oxide: Fundamentals, Materials and Device Technology, Willey-VCH, Weinheim, 2009; b) A. B. Djurišić, Y. H. Leung, Small 2006, 2, 944-961; c) C. Klingshirn, ChemPhysChem 2007, 8, 782 803; d) B. Ludi, M. Niederberger Dalton Trans. 2013, 42, 12554-12568 e) S. G. Kumar, K. S. R. K. Rao, RSC Adv. 2015, 5, 3306-3351.

[2] For selected examples, see: a) L. Spanhel, M. A. Anderson, J. Am. Chem. Soc. 1991, 113, 2826-2833; b) E. A. Meulenkamp, J. Phys. Chem B 1998, 102, 5566-5572; c) C. Pacholski, A. Kornowski, H. Weller, Angew. Chem. Int. Ed. 2002, 41, 1188; d) Y.-S. Fu, X.-W. Du, S. A Kulinich, J.-S. Qiu, W.-J. Qin, R. Li, J. Sun, J. Liu, J. Am. Chem. Soc. 2007, 129, 16029-16033; e) M. Yang, K. Sun, N. A. Kotov J. Am. Chem. Soc. 2010, 132, 1860-1872.

[3] For example, see: a) M. S. Tokumoto, S. H. Pulcinelli, C. V. Santilli, V. Briois, J. Phys. Chem. B 2003, 107, 568-574; b) M. Voigt, M. Klaumunzer, H. Thiem, W. Peukert, J. Phys. Chem. C 2010, 114, 6243 6249 ; c) B. L. Caetano, C. V. Santilli, F. Meneau, V. Briois, S. H. Pulcinelli, J. Phys. Chem. C 2011, 115, 4404-4412; d) A. Layek, G. Mishra, A. Sharma, M. Spasova, S. Dhar, A. Chowdhury, R. Bandyopadhyaya, J. Phys. Chem. C 2012, 116, 24757- 24769; e) T. Schindler, J. Walter, W. Peukert, D. Segets, T. Unruh, J. Phys. Chem. B 2015, 119, 15370-15380.

[4] Note that colloidal surfaces structure of ZnO NCs derived from sol-gel methodology is not yet well understood and its determination is still challenging, see: a) S. Sakohara, M. Ishida, M.A. Anderson, J. Phys. Chem. B 1998, 102, 10169-10175; b) D. Segets, R. Marczak, S. Schäfer, C. Paula, J.-F. Gnichwitz, A. Hirsch, W. Peukert, ACS Nano 2011, 5, 4658-4669; c) C. N. Valdez, A. M. Schimpf, D. R. Gamelin, J. M. Mayer,
ACS Nano 2014, 8, 9463-9470; d) M. Zobel, R. B. Neder, S. A. J. Kimber, Science 2015, 347, 292-294; e) T. Schindler, M. Schmiele, T. Schmutzler, T. Kassar, D. Segets, W. Peukert, A. Radulescu, A. Kriele, R. Gilles, T. Unruh, Langmuir 2015, 31, 10130-10136; f) M. Gong, Q. Liu, B. Cook, B. Kattel, T. Wang, W.-L. Chan, D. Ewing, M. Casper, A. Stramel, J. Z. Wu, ACS Nano 2017, 11, 4114-4123.

[5] a) M. Monge, M. L. Kahn, A. Maisonnat, B. Chaudret, Angew. Chem Int. Ed. 2003, 42, 5321-5324; b) M. L. Kahn, M. Monge, V. Collière, F. Senocq, A. Maisonnat, B. Chaudret, Adv. Funct. Mater. 2005, 15 458-468; c) Y. Coppel, G. Spataro, V. Collière, B. Chaudret, C Mingotaud, A. Maisonnat, M. L. Kahn, Eur. J. Inorg. Chem. 2012 2691-2699; d) Y. Coppel, G. Spataro, C. Pagès, B. Chaudret, A. Maisonnat, M. L. Kahn, Chem. Eur. J. 2012, 18, 5384-5393.

[6] K. L. Orchard, M. S. P. Shaffer and C. K. Williams, Chem. Mater. 2012 24, 2443-2448.

[7] Moreover, different chemical environments for the oxygen atoms are characterized and a dynamic exchange process between the $\mathrm{ZnO}$ NCs and the external environment was also evidenced and analyzed using ${ }^{17}$ O MAS NMR spectroscopy. Y. Champouret, Y. Coppel, M. L. Kahn, J. Am. Chem. Soc. 2016, 138, 16322-16328

[8] a) J. Paczesny, M. Wolska-Pietkiewicz, I. Binkiewicz, Z. Wróbel, M. Wadowska, K. Matuła, I. Dzięcielewski, D. Pociecha, J. SmalcKoziorowska, J. Lewiński, R. Hołyst, Chem. Eur. J. 2015, 21, 16941 16947; b) A. Grala, M. Wolska-Pietkiewicz, W. Danowski, Z. Wróbel, J. Grzonka, J. Lewiński, Chem. Commun. 2016, 52, 7340-7343; c) M. Wolska-Pietkiewicz, A. Grala, I. Justyniak, D. Hryciuk, M. Jędrzejewska, J. Grzonka, K. Kurzydłowski, J. Lewiński, Chem. Eur. J. 2017, 49, 1185611865; d) E. Chwojnowska, M. Wolska-Pietkiewicz, J. Grzonka, J. Lewiński, Nanoscale, 2017, 9, 14782-14786; e) M. Wolska-Pietkiewicz, K. Tokarska, A. Grala, A. Wojewódzka, E. Chwojnowska, J. Grzonka, P. Cywiński, K. Kruczała, Z. Sojka, M. Chudy, J. Lewiński, Chem. Eur. J. 2017, 24, 4033-4042.

[9] A. M. Cieślak, M. V. Pavliuk, L. D’Amario, M. Abdellah, K. Sokołowski, U. Rybińska, D. L. A. Fernandes, M. K. Leszczyński, F. Mamedov, A. M. ElZhory, J. Föhlinger, A. Budinská, M. Wolska-Pietkiewicz, L. Hammarström, J. Lewiński, Jacinto Sá, Nano Energy 2016, 30, 187-192.

[10] a) D. A. Hall, D. C. Maus, G. J. Gerfen, S. J. Inati, L. R. Becerra, F. W. Dahlquist, R. G. Griffin, Science, 1997, 276, 930-932; b) D. Lee, S. Hediger, G. De Paëpe in Modern Magnetic Resonance (Eds. G. A. Webb), Springer, 2017 pp. 1-17.

[11] a) A. Lesage, M. Lelli, D. Gajan, M. A. Caporini, V. Vitzthum, P. Miéville, J. Alauzun, A. Roussey, C. Thieuleux, A. Mehdi, G. Bodenhausen, C Coperet, L. Emsley, J. Am. Chem. Soc. 2010, 132, 15459-15461; b) A. J. Rossini, A. Zagdoun, M. Lelli, A. Lesage, C. Copéret, L. Emsley, Acc. Chem. Res. 2013, 46, 1942-1951; c) D. Lee, G. Monin, N. T. Duong, I. Z. Lopez, M. Bardet, V. Mareau, L. Gonon, G. De Paëpe, J. Am. Chem. Soc. 2014, 136, 13781-13788.

[12] a) L. Piveteau, T.-C. Ong, A. J. Rossini, L. Emsley, C. Copéret, M. V. Kovalenko, J. Am. Chem. Soc. 2015, 137, 13964-13971; b) L. Piveteau, T. C. Ong, B. J. Walder, D. N. Dirin, D. Moscheni, B. Schneider, J. Bär, L. Protesescu, N. Masciocchi, A. Guagliardi, L. Emsley, C. Copéret, M. V. Kovalenko, ACS Cent. Sci. 2018, 4, 1113-1125.

[13] Note that higher ligand packing density for the-SG NCs could be defined by both roughness of surface structure and/or presence of a 'swollen' organic ligand shell (cf. ref. 4d). Moreover, TGA is an effective method which provide insight into the true value of the grafting density as well as the magnitude of the methodological systematic errors, for example a simplified model of sphere is applied (however, the SG NCs are irregulary-shaped): a) D. N. Benoit, H. Zhu, M. H. Lilierose, R. A. Verm, N. Ali, A. N. Morrison, J. D. Fortner, C. Avendano, V. L. Colvin, Anal Chem. 2012, 84, 9238-9245.

[14] a) H. Al-Johani, E. Abou-Hamad, A. Jedidi, C. M. Widdifield, J. VigerGravel, S. S. Sangaru, D. Gajan, D. H. Anjum, S. Ould-Chikh, M. N Hedhili, A. Gurinov, M. J. Kelly, M. El Eter, L. Cavallo, L. Emsley, J.-M. Basset, Nat. Chem. 2017, 9, 890 - 895; b) Z. Pang, J. Zhang, W. Cao, X. Kong, X. Peng, Nat. Commun. 2019, https://doi.org/10.1038/s41467019-10389-5.

[15] M. Wolska-Pietkiewicz, A. Świerkosz, I. Justyniak, A. Grala, K. Sokołowski, J. Lewiński, Dalton Trans. 2016, 45, 18813-18816.

[16] Potentially glycerol might play an analogous role as catechol molecules, which provide an effective and versatile way to modify sol-gel derived 
zinc oxide surfaces by means of ligand exchange reactions a) W. Lin, J Walter, A. Burger, H. Maid, A. Hirsch, W. Peukert, D. Segets, Chem. Mater. 2015, 27, 358-369; b) A. Burger, R. Srikantharajah, W. Peukert, A. Hirsch, Chem. Eur. J. 2017, 23, 17257-17268.

[17] a) G. Teymoori, B. Pahari, B. Stevensson, M. Edén, Chem. Phys. Lett. 2012, 547, 103-109; b) G. Teymoori, B. Pahari, M. Edén, J. Magn. Reson. 2015, 261, 205-220.
[18] M. Veshtort, R. G. Griffin, J. Magn. Reson. 2006, 178, 248-282

[19] N. J. Nicholas, G. V. Franks, W. A. Ducker, Langmuir 2012, 28, 7189 7196 
Entry for the Table of Contents (Please choose one layout)

Layout 1:

\section{COMMUNICATION}

Strong and stable. $\mathrm{ZnO}$ nanocrystals derived through a one-pot self-supporting organometallic (OSSOM) approach produce a stable and organized surfaceligand union. Conversely, a more traditional sol-gel approach provides a limited presence of random but stable cold spots with the majority of native ligands having their surface-supporting roles taken by foreign solvent molecules, resulting in a swollen shell around the $\mathrm{ZnO}$. This highlights the superiority of the OSSOM approach for the preparation of high quality quantum-sized $\mathrm{ZnO}$ crystals.

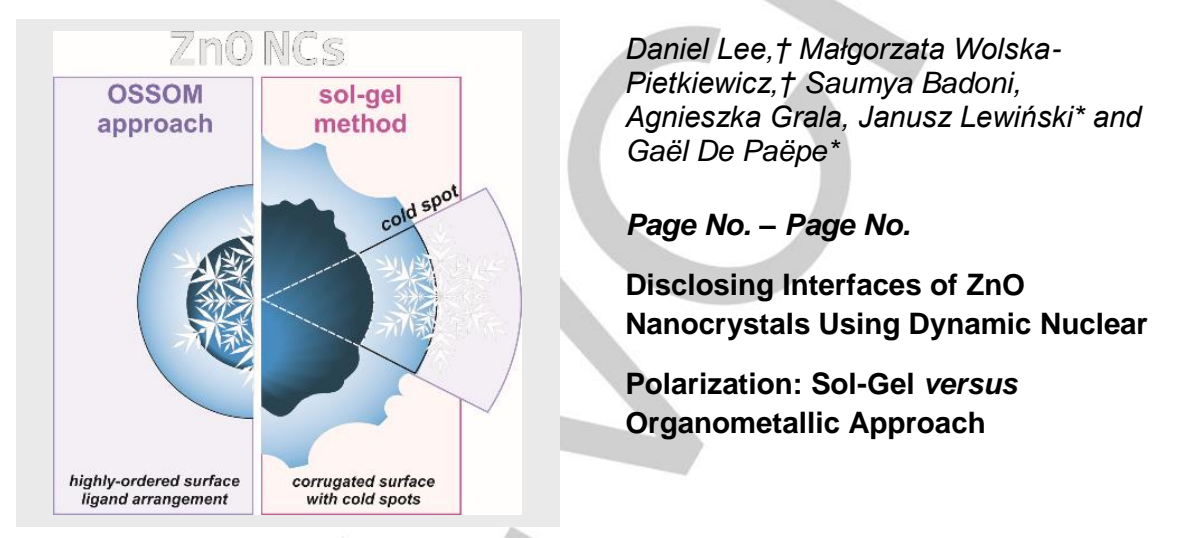

